\title{
Jogos digitais ou desplugados: brincadeira ou coisa séria?
}

Vanessa Lima Bertolazi Simon vlbsimon@furb.br

0000-0002-9461-717X

Universidade Regional de Blumenau,

Blumenau, Santa Catarina, Brasil.

\section{Alexandre Simon}

asimon@furb.br

0000-0002-3051-5537

Universidade Regional de Blumenau,

Blumenau, Santa Catarina, Brasil.

Janaína Poffo Possamai

janainap@furb.br

0000-0003-3131-9316

Universidade Regional de Blumenau,

Blumenau, Santa Catarina, Brasil.

\section{RESUMO}

Neste artigo apresentam-se algumas narrativas acerca da infância e o lúdico, a partir da ótica histórica, possibilitando uma breve análise da utilização dos jogos como ferramenta no ensino e aprendizagem da Matemática. Sob esta perspectiva, este trabalho tem como intuito avaliar quais as implicações e qual a preferência das crianças quando utilizado o jogo como ferramenta de ensino, tanto no formato digital, utilizando a plataforma Kahoot!, como na versão do mesmo sob forma desplugada (manual). Para tanto, foi aplicado um jogo, com o intuito de promover o desenvolvimento do cálculo mental referente as quatro operações fundamentais, em uma turma do segundo ano do Ensino Fundamental. Os resultados indicam que, independente da forma do jogo, os interesses estão relacionados à particularidade da situação e não ao formato de apresentação. Em relação à aprendizagem, o desenvolvimento do cálculo mental foi estimulado igualmente nas duas versões do jogo, favorecendo o trabalho em grupo, o desenvolvimento das habilidades de resolução de problemas e de tomada de decisão.
\end{abstract}

PALAVRAS-CHAVE: Jogos didáticos. Ensino de Matemática. Kahoot. 


\section{INTRODUÇÃO}

Faz parte da condição humana o desenvolvimento de atividades lúdicas, sejam elas através de jogos ou brincadeiras, independente da idade do indivíduo. Estas atividades, por sua vez, visam promover a satisfação pelo simples fato da ação, observadas em diferentes contextos que já desempenhamos em nosso cotidiano.

O jogo assume um papel fundamental no desenvolvimento da criança, principalmente no que tange aos estágios cognitivos envolvidos, bem como podem ser considerados relevantes para uso didático, auxiliando no processo de ensino e aprendizagem, levando em conta, seu papel social e metodológico (GRANDO, 2015), uma vez que os jogos "[...] desenvolvem a capacidade de elaborar estratégias, solucionar problemas e promovem momentos de interações sociais" (OLIVEIRA; BRIM; PINHEIRO, 2019, p. 570).

Os jogos utilizados no contexto de brincadeira das crianças e, também como recurso de ensino, perpassam pela crescente utilização de recursos tecnológicos. Vivemos em meio à Tecnologia da Informação e Comunicação (TIC). Desta forma, nada mais natural que procurar entendê-las e aplicá-las em nosso dia a dia, utilizando-as como fonte de conhecimento ou como ferramenta na inserção de conteúdos diversificados. Atualmente, por meio da tecnologia, o aprendizado está longe de acontecer somente dentro da escola. Fontes de informação estão cada vez mais acessíveis a todos, possibilitando condições para uma educação de forma ampla e condizente com a realidade. Silva e $\operatorname{Scheffer}(2019$, p. 13$)$ ressaltam que o "[...] o potencial educativo das tecnologias digitais ao ensino da Matemática constitui uma proposta pedagógica contemporânea e, neste contexto, é importante destacarmos o mérito dos jogos digitais como recurso didático".

Nesse contexto, o aprendizado acontece sob diferentes aspectos, seja por meio da tecnologia, com a família, amigos e na sociedade em que se está inserido. A utilização das Tecnologias da Informação e Comunicação (TIC) em nosso cotidiano, possibilita um novo conceito de educação, voltada ao uso de alternativas e ferramentas midiáticas, que propiciem a transformação social e cultural do indivíduo.

\footnotetext{
Muitas vezes, não vemos sentido no que estamos ensinando. E nossos alunos também não veem sentido no que estão aprendendo. Numa época de incertezas, de perplexidades, de transição, esse profissional deve construir sentido com seus alunos. $O$ processo ensino/aprendizagem deve ter sentido para o projeto de vida de ambos, para que seja um processo verdadeiramente educativo. O grande mal-estar de muitos de nossos professores e nossas escolas está no 'viver sem sentido' do que estão fazendo. $O$ ato educativo está essencialmente ligado ao viver com sentido, à impregnação de sentido para nossas vidas (GADOTTI, 2005, p. 55).
}

O jogo, seja ele digital ou não, está intimamente ligado a um ambiente estimulante para a criança, não somente por conta dos objetos envolvidos, mas pelas regras que os constituem. Os desafios impostos vêm de encontro a uma situação favorável ao desenvolvimento do pensamento abstrato (GRANDO, 2000).

Este trabalho se insere nos desafios que a escola contemporânea enfrenta acerca da elaboração e diversificação de estratégias para que o ensino e aprendizagem das crianças realmente façam parte do seu cotidiano, através do uso de jogos como ferramenta didática. Este ensaio visa analisar o jogo Kahoot!, sob a forma digital e desplugada (manual), avaliando quais as implicações para a 
construção do cálculo mental referente as quatro operações fundamentais, bem como analisar as diferenças e as preferências em relação às duas versões.

\section{O JOGO - DO LÚDICO AO RECURSO DE APRENDIZAGEM}

Etimologicamente, a palavra jogo, provém do vocábulo latino iocus, que significa brincadeira, graça, diversão, frivolidade, rapidez, passatempo, embora possua outros significados, como do vocábulo ludus-i: o ato de jogar, o prazer da dificuldade gratuita. $O$ vocábulo latino permite fornecer mais um sentido ao jogo: ludus-ludere, ludus-us e ludicrus (ou cer-cra, crum). Destacando ainda o conceito lúdico (do latim ludicrus), que agrega ao jogo um aspecto de atividade secundária, a qual se utiliza pelo simples fato de dar prazer, assim como, a palavra jugar (do latim iocari) significa fazer algo com espírito de alegria e com a intenção de se divertir ou de se entreter (FUENTES, 2005). Segundo Ortiz (2005) a raiz do vocábulo jogo aparece também em indo europeu como *aig-, que significa duvidar, oscilar e mover-se.

De acordo com Fuentes (2005) há outras diferentes raízes para se referenciar ao jogo. Entre elas está o sânscrito, o qual utiliza o termo kridati. Este por sua vez, descreve o jogo das crianças, dos adultos e dos animais, podendo ser utilizado para outras definições como o agitar do vento, das ondas, saltos e danças de modo geral.

Segundo Ortiz (2005), a atividade lúdica é tão antiga quanto a espécie humana e o jogo sempre esteve presente nas mais diversas ocasiões e praticamente em todas as culturas existentes. $O$ autor ainda destaca que a cultura de um povo pode ser expressa da maneira como desenvolve um determinado jogo. E que isso ocorre desde a infância, quando se joga esporadicamente ou não, mas que este processo auxilia no desenvolvimento do infante, na sua constituição como sujeito, até a fase adulta.

Segundo Brougère (1998) cada cultura estabelece um desígnio para o jogo, ou seja, o ludus latino não é parecido ao brincar francês, o qual podem estar próximos ao termo de brincar, opondo-se a trabalhar, e embora pareça uma atividade infantil, está ligada diretamente a vida social de cada indivíduo. Ortiz (2005) destaca o fenômeno antropológico do jogo no estudo do ser humano, estando intrínseco a cultura, a história, costumes e a literatura, fazendo parte do vínculo entre determinados povos e servindo como um importante facilitador da comunicação entre os indivíduos.

O jogo está vinculado a aprendizagem e comunicação, sendo utilizado como ferramenta no desenvolvimento da capacidade psicomotora, próprios da idade infantil. Através do jogo a criança aprende divertindo-se, interage com seus pares e envolve-se com o processo educativo, além de promover "[...] um ambiente rico que enaltece a interação social, o raciocínio lógico e a tomada de decisão" (SILVA, et al., 2015, p. 89).

Fuentes (2005) reforça que o jogo na escola deve atender a duas funções específicas. Uma está relacionada ao conteúdo e outra trata da finalidade propriamente dita, justamente para alcançar a aprendizagem e o desenvolvimento do indivíduo como um todo. $O$ autor destaca que o jogo é a primeira expressão da criança. Desta forma, aproveitar para ensinar sob a ótica da espontaneidade do jogar da criança é tornar o ensino simples e de fácil entendimento. 
Quando uma criança entra na escola, ela não é tábula rasa que possa ser moldada pelo professor segundo a forma que ele preferir. Essa placa já contém as marcas daquelas técnicas que a criança usou ao aprender a lidar com os complexos problemas de seu ambiente. Quando uma criança entra na escola, já está equipada, já possui suas próprias habilidades culturais. Mas este equipamento é primitivo e arcaico; ele não foi forjado pela influência sistemática do ambiente pedagógico, mas pelas próprias tentativas primitivas feitas pela criança para lidar, por si mesma, com tarefas culturais (LEONTIEV, 1998, p. 101).

De acordo com Huizinga (1996), o jogo e suas características imaginativas promove a criatividade, o desenvolvimento humano, destacando sua importância no processo de ensino e aprendizagem. Salienta que os jogos estão incorporados ao processo de ensino e aprendizagem desde a infância. Por conta do envolvimento das crianças através da brincadeira, o aprendizado pode tornar-se prazeroso e significativo nas diferentes fases da vida.

De acordo com estudos acerca da psique infantil, é possível analisar e compreender o desenvolvimento das atividades das crianças, elucidando suas potencialidades com vistas ao papel condutor da educação, verificando a própria atividade infantil de acordo com sua realidade e nível de consciência (LEONTIEV, 1998).

Leontiev (1998) destaca a diferenciação de um estágio de desenvolvimento infantil a outro, em que a atividade principal da criança passa a ser uma relação dominante com sua realidade. Esta atividade, por sua vez, é aquela a qual a criança dedica maior parte do seu tempo e está intimamente ligada a determinados atributos:

1- A criança aprende por meio da brincadeira;

2- A criança aprende quando sua atividade principal toma forma e se reorganiza. Através de desenhos associados à atividade lúdica;

3- Pelo brinquedo, a criança assimila as funções sociais das pessoas e padrões apropriados de comportamento.

A palavra jogo aparece como uma simples atividade humana, assim como o ato de comer ou dormir. A complexidade do termo é atribuída, ao tentar explicar a natureza do ser humano. Fuentes (2005) considera que esta palavra está presente em nosso cotidiano e é sinônimo de conduta humana, mantendo-se em constante movimento e crescimento.

Há diferentes tipos de jogos, entre eles os de entretenimento e os que fazem uso desta potencialidade para a aplicação de conteúdos, permitindo um ambiente de aprendizagem estruturado e dinâmico (DAMBRÓs; MOURAD, 2017).

[...] para fins educativos, os jogos necessitam ter objetivos de aprendizagem bem definidos, ou seja, é preciso definir o que a criança aprenderá ao jogar. Assim, é possível desenvolver habilidades importantes e ampliar a capacidade cognitiva das crianças, uma vez que a aprendizagem ocorre de forma diferente das práticas tradicionais (DAMBRÓS; MOURAD, 2017, p. 123).

Grando (2015) discute acerca da possibilidade de unir o ensino à brincadeira, e, desta forma, atingir um único objetivo: o de atender o desenvolvimento do indivíduo nos diferentes estágios de sua vida. Especificamente na fase infantil, o jogo se apresenta como parte do processo de desenvolvimento, atribuído às funções psicossociais, afetivas e intelectuais. E, ao analisar uma criança através de 
uma brincadeira, verifica-se o quanto sua capacidade de raciocínio é estimulada pelo fato de questionar, buscar soluções, resolver problemas e interagir com seus pares.

\section{UTILIZANDO O KAHOOT!}

O desenvolvimento da ferramenta Kahoot! partiu de Alf Inge Wang, professor de Ciência da Computação e Tecnologia de Jogos da Universidade Norueguesa de Tecnologia e Ciência (NTNU) em Trondheim, Noruega. A princípio a ideia chamavase Lecture Quis, em 2006. A partir dos estudos de mestrado de Morten Versvik, o aluno de Wang tornou-se co-fundador, juntamente com Jamie Brooker, Johan Brand e Asmund Furuseth, formando a empresa e trabalhando na UX e no design da Kahoot!. Em março de 2013 a versão beta do Kahoot! foi lançada em SXSW EDU em Austin e, formalmente, em agosto de 2013 (KAHOOT!, 2018).

De acordo com Johan Brand, o Kahoot! é uma ferramenta que busca unir a tecnologia aos elementos de aprendizagem trazendo para esta temática uma versão dinâmica e descontraída.

No site da plataforma há a possibilidade de escolher qual a forma do jogo que melhor atende as necessidades do planejamento do professor. Silva et al. (2018) apresentam de forma simplificada cada uma delas:

Quiz: são questionários de múltipla escolha com correção automática, buscando avaliar de forma rápida e divertida. Propicia feedbacks imediatos, tanto para o aluno quanto para o professor. Ao final da atividade é possível obter um relatório geral dos participantes, identificando possíveis dificuldades dos alunos, possibilitando ao professor intervir e retomar determinadas questões para o entendimento de todos.

Discussion: esta opção permite a colocação de uma única questão, com várias opções de resposta, podendo ter várias respostas corretas. Pode ser utilizada em aula ou palestras, em que durante a apresentação é possível fazer perguntas aos ouvintes sem a interrupção para a resposta. Ao final é gerado um registro que pode ser analisado posteriormente pelo professor.

Survey: é uma opção que pode ser utilizada para sondagem de uma turma acerca de um determinado tema. Neste caso não há opções corretas ou incorretas. É uma opção interessante para o professor para traçar um diagnóstico de uma turma e obter uma resposta rápida e clara.

Jumble: é a versão mais recente, em que se faz uso da opção do Quiz clássico, mais centrada no usuário. Pois além da resposta estar correta, o usuário deve ficar atento à ordem da resposta, que também deverá estar correta, montando um quebra-cabeça, propiciando um desafio ao jogador e aumentando a dificuldade lógica ao escolher sua opção.

A plataforma Kahoot! fornece um ambiente de aprendizagem, onde professores, alunos e demais pessoas possam acessar e usufruir da mesma. Esta propicia ferramentas para a criação de jogos, de acordo com necessidade, conteúdo e objetivos do professor. Além da possibilidade da criação, ainda há uma série de jogos prontos que podem ser utilizados. Esta plataforma é gratuita e pode ser utilizada individualmente ou em grupos, dependendo da proposta para qual o jogo será criado. 
Prensky (2012) considera que a aprendizagem baseada em jogos, será extremamente normal daqui há alguns anos, visto a facilidade no aprendizado e acessibilidade que os meios digitais já oferecem. $\mathrm{O}$ autor ainda elenca três motivos que o fazem acreditar que este processo ocorre e ocorrerá, com velocidade cada vez maior. Estes motivos são:

1- Atender às necessidades e aos diferentes estilos de aprendizagem que compõem a atual e futuras gerações;

2- É motivante e divertida;

3- É extremamente versátil, adaptando-se à maior parte das disciplinas, bem como aos conteúdos trabalhados em cada uma, favorecendo o aprendizado, desenvolvendo habilidades e sendo incrivelmente eficaz.

A escola, por sua vez, deve utilizar as possibilidades, competências e habilidades dos alunos, valorizando seu contexto e suas experiências e compreender que a educação é um dos aspectos dos mecanismos formadores da natureza e assim integrar o processo educativo a um sistema que constitui o eixo fundamental de todo o processo de ensino (Soëtard, 2010). Sendo assim, reafirma que o processo educativo não está vinculado à escola ou à família e que o desenvolvimento do ser ocorre ao longo de sua vida em sociedade.

\section{CARACTERIZAÇÃO DA PESQUISA}

Este trabalho será desenvolvido seguindo os princípios da pesquisa qualitativa de Bogdan e Biklen (1991), a qual constará de um estudo de caso de observação participante, contemplando a observação para coleta de dados, centrando na escola como ambiente a ser investigado. Para coleta de dados foram utilizados os seguintes instrumentos: fotos, vídeos, registros elaborados pelos estudantes e diário de campo.

Inicialmente foi realizada uma pesquisa bibliográfica, buscando fundamentação teórica para o tema abordado. A partir desta pesquisa os jogos foram elaborados, respeitando idade/série dos alunos. A aplicação do jogo foi realizada em uma escola pública na cidade de Balneário Camboriú / SC, em uma turma do segundo ano do Ensino Fundamental composta por 21 alunos, com idade entre 7 e 8 anos. 0 intuito desse jogo foi contribuir para o desenvolvimento do cálculo mental referente as quatro operações fundamentais.

Esta pesquisa baseou-se na opção Quis do Kahoot!, que permite escolher a resposta correta entre as duas opções que adicionamos. $O$ jogo foi elaborado com questões acessíveis à idade dos alunos.

Uma versão desplugada (manual) do jogo também foi construída com a finalidade de realizar um comparativo com a versão digital. Destaca-se que o entendimento de desplugado está de acordo com Brackmann (2017, p. 50) ao indicar que "[...]as atividades desplugadas ocorrem frequentemente através da aprendizagem cinestésica (e.g. movimentar-se, usar cartões, recortar, dobrar, colar, desenhar, pintar, resolver enigmas, etc.)".

Como critérios de comparação na utilização dos dois jogos, avaliou-se o interesse e a aprendizagem dos alunos. $\mathrm{Na}$ sequência discute-se o desenvolvimento desses jogos bem como sua aplicação. 
A turma foi dividida em sete grupos, cada um representado por uma cor e cada cor composta por três alunos. No Laboratório de Informática a plataforma foi colocada em rede e os alunos foram orientados a escolher a opção Team mode. Em seguida os alunos tiveram acesso a um número PIN que digitaram em seus computadores.

Posteriormente, cada grupo escreveu sua cor correspondente e os nomes dos participantes. Quando todos os grupos fizeram este acesso o jogo começou.

Ao analisar a questão o grupo teve que escolher a resposta certa, de acordo com a forma geométrica e sua cor correspondente. Ao final de cada questão, foi atribuído um score, o qual identificou quais são os grupos que acertaram e conseguiram responder a questão em menos tempo.

\section{O Jogo Desplugado (no pátio da escola)}

O mesmo jogo digital foi reestruturado para a forma desplugada, a qual não utiliza computadores para sua execução. Foram confeccionados painéis com as perguntas e cada equipe recebeu duas cartas com as formas geométricas e cores semelhantes ao do jogo digital, para que, de acordo com a resposta que acreditassem ser a correta, levassem a carta (forma geométrica) que identificasse sua resposta. A Figura 1 ilustra uma das perguntas com as opções de resposta apresentadas e as cartas de respostas dos estudantes, sendo que eles deveriam apresentar uma delas.

Figura 1 - Painéis com as perguntas e placas de respostas

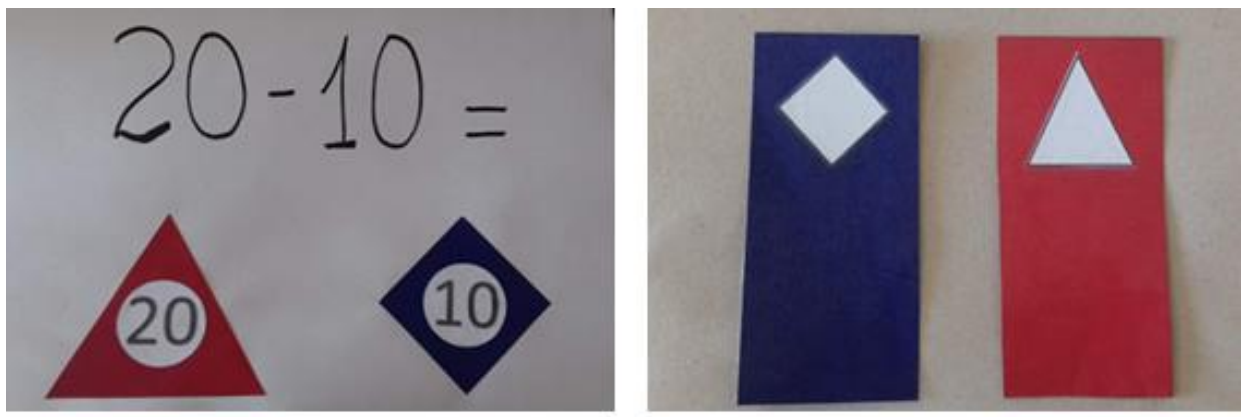

Fonte: Arquivo dos autores.

Na hora da resposta um dos integrantes de cada grupo levou a sua opção de resposta para o professor, que anotou a ordem de chegada das respostas dos grupos. Assim era conferido a resposta e atribuída uma pontuação maior ao primeiro que entregasse corretamente, em relação à pontuação dos demais que acertaram. A planilha de registro foi organizada com o número da pergunta, se acertou ou não, o status de chegada e o total de pontos adquiridos.

\section{RESULTADOS E DISCUSSÃO}

Grando (2000, p. 43) apresenta alguns momentos do jogo e indica que os mesmos devem ser "[...] considerados na realização das atividades de intervenção com jogos em situações de sala de aula". Esses momentos estão descritos na Tabela 1, com as orientações indicadas por Grando, contendo os registros realizados do jogo digital e desplugado analisados nessa pesquisa. 
Tabela 1 - Comparação da teoria de Grando (2000) com a prática

\begin{tabular}{|c|c|c|}
\hline $\begin{array}{l}\text { Momento de } \\
\text { jogos }\end{array}$ & Teoria Grando (2000, p. 43-45) & Prática \\
\hline Familiarização & $\begin{array}{l}\text { A princípio, os alunos entram } \\
\text { em contato com o material do } \\
\text { jogo, identificando materiais } \\
\text { conhecidos, como: dados, } \\
\text { peões, tabuleiros e outros, e } \\
\text { experimentam o material } \\
\text { através de simulações de } \\
\text { possíveis jogadas. }\end{array}$ & $\begin{array}{l}\text { Digital: os alunos entraram em } \\
\text { contato com uso do teclado e } \\
\text { mouse, para escrever seus nomes } \\
\text { e escolher a opção adequada. } \\
\text { Desplugado: visualizaram como } \\
\text { seria a utilização dos painéis com } \\
\text { as perguntas e como fariam para } \\
\text { escolher a resposta com as placas. }\end{array}$ \\
\hline $\begin{array}{l}\text { Reconheciment } \\
\text { o das Regras e } \\
\text { o jogo pelo jogo }\end{array}$ & $\begin{array}{l}\text { São explicadas pelo orientador } \\
\text { da ação ou lidas, ou ainda, } \\
\text { identificadas através da } \\
\text { realização de várias partidas- } \\
\text { modelo, onde o orientador da } \\
\text { ação pode jogar várias partidas } \\
\text { seguidas com um dos alunos. }\end{array}$ & $\begin{array}{c}\text { Digital: Foi exibido um modelo } \\
\text { para que houvesse o } \\
\text { entendimento das regras. } \\
\text { Desplugado: As regras foram } \\
\text { discutidas com os alunos e } \\
\text { simuladas através de uma jogada } \\
\text { para melhor entendimento. }\end{array}$ \\
\hline $\begin{array}{l}\text { Intervenção } \\
\text { pedagógica } \\
\text { verbal }\end{array}$ & $\begin{array}{l}\text { Trata-se das intervenções que } \\
\text { são realizadas verbalmente, } \\
\text { pelo orientador da ação, } \\
\text { durante o movimento do jogo. }\end{array}$ & $\begin{array}{c}\text { Em ambos os jogos a adaptação e } \\
\text { o entendimento foram rápidos, } \\
\text { não gerando dúvidas, não sendo } \\
\text { necessário intervenção. }\end{array}$ \\
\hline Registro do Jogo & $\begin{array}{l}\text { É o registro dos pontos, ou } \\
\text { mesmo dos procedimentos } \\
\text { utilizados. }\end{array}$ & $\begin{array}{c}\text { Em ambas as versões não houve } \\
\text { registro escrito dos } \\
\text { procedimentos do jogo. }\end{array}$ \\
\hline $\begin{array}{l}\text { Intervenção } \\
\text { escrita }\end{array}$ & $\begin{array}{l}\text { É o momento de descrever } \\
\text { possíveis situações-problemas. } \\
\text { O registro do jogo está presente } \\
\text { neste momento. }\end{array}$ & $\begin{array}{c}\text { Em ambos os jogos a descrição da } \\
\text { análise do jogo somaram-se a } \\
\text { perguntas feitas verbalmente. }\end{array}$ \\
\hline $\begin{array}{l}\text { Jogar com } \\
\text { competência }\end{array}$ & $\begin{array}{l}\text { Um último momento } \\
\text { representa o retorno à situação } \\
\text { real de jogo, considerando } \\
\text { todos os aspectos } \\
\text { anteriormente analisados } \\
\text { (intervenções). É importante } \\
\text { que o aluno retorne à ação do } \\
\text { jogo para que execute muitas } \\
\text { das estratégias definidas e } \\
\text { analisadas durante a resolução } \\
\text { dos problemas. }\end{array}$ & $\begin{array}{l}\text { Cada um dos jogos foi executado } \\
\text { somente uma vez, o que não nos } \\
\text { permitiu fazer esta análise } \\
\text { posterior. }\end{array}$ \\
\hline
\end{tabular}

Fonte: Elaborado pelos autores.

Grando (2015) ressalta o valor dos jogos pedagógicos no processo de ensino e de aprendizagem, independentemente do tipo escolhido. Pode-se dizer que todos possuem papel fundamental no ensino, desde que utilizados para esta função.

Desta forma, é importante ressaltar que o jogo vai além de uma simples brincadeira e a escola precisa estar atenta às metodologias e práticas 
diferenciadas, envolvendo seus alunos com aquilo que eles já conhecem. Valorizar a brincadeira significa dar a oportunidade da criança "ser criança".

A partir desta premissa analisou-se os gráficos realizados acerca dos resultados obtidos nos jogos.

Na Figura 2, constam as pontuações dos grupos no jogo digital, sendo que o que mais acertou foi também o que respondeu rapidamente.

Figura 2 - Gráfico do grupo que ganhou no jogo digital

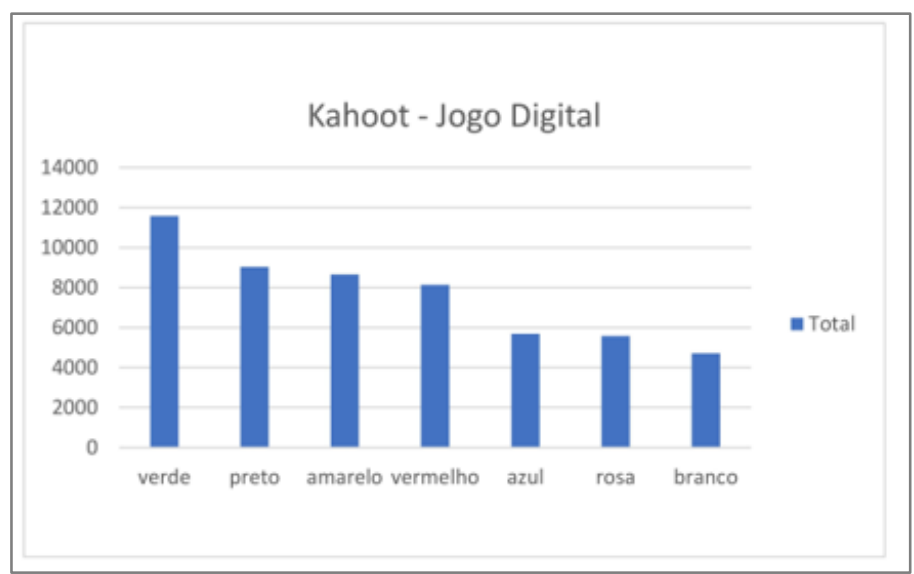

Fonte: Elaborado pelos autores.

Na Figura 3 é possível verificar que o grupo que acertou mais questões e respondeu com maior rapidez foi o grupo vermelho, analisando os resultados do jogo desplugado.

Figura 3 - Gráfico do grupo que ganhou no jogo desplugado (pátio)

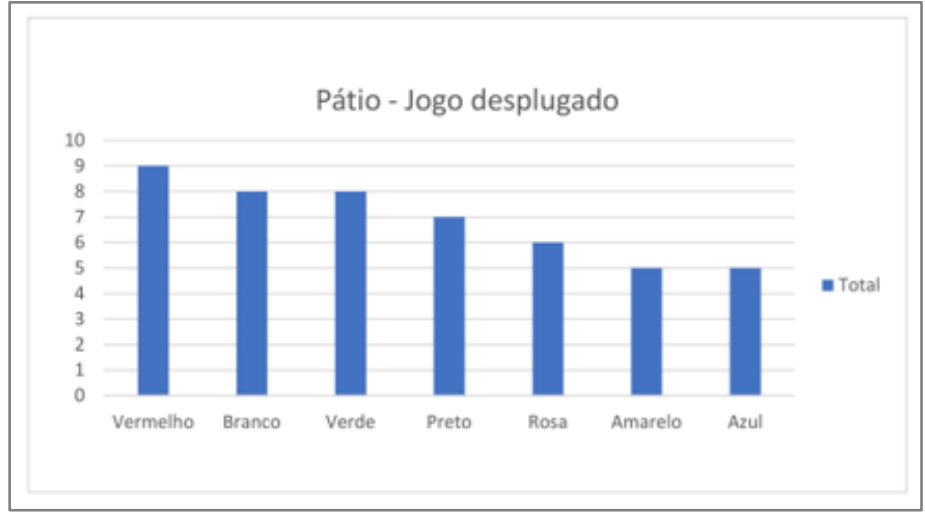

Fonte: Elaborado pelos autores.

Na Figura 4 constam as perguntas feitas aos alunos, para que se pudesse verificar qual a preferência entre os jogos digitais e/ou desplugados. $\mathrm{O}$ questionário contou com quatro perguntas, sendo usada a pergunta Q3 como controle. 
Figura 4 - Esboço das perguntas feitas para analisar a preferência dos alunos

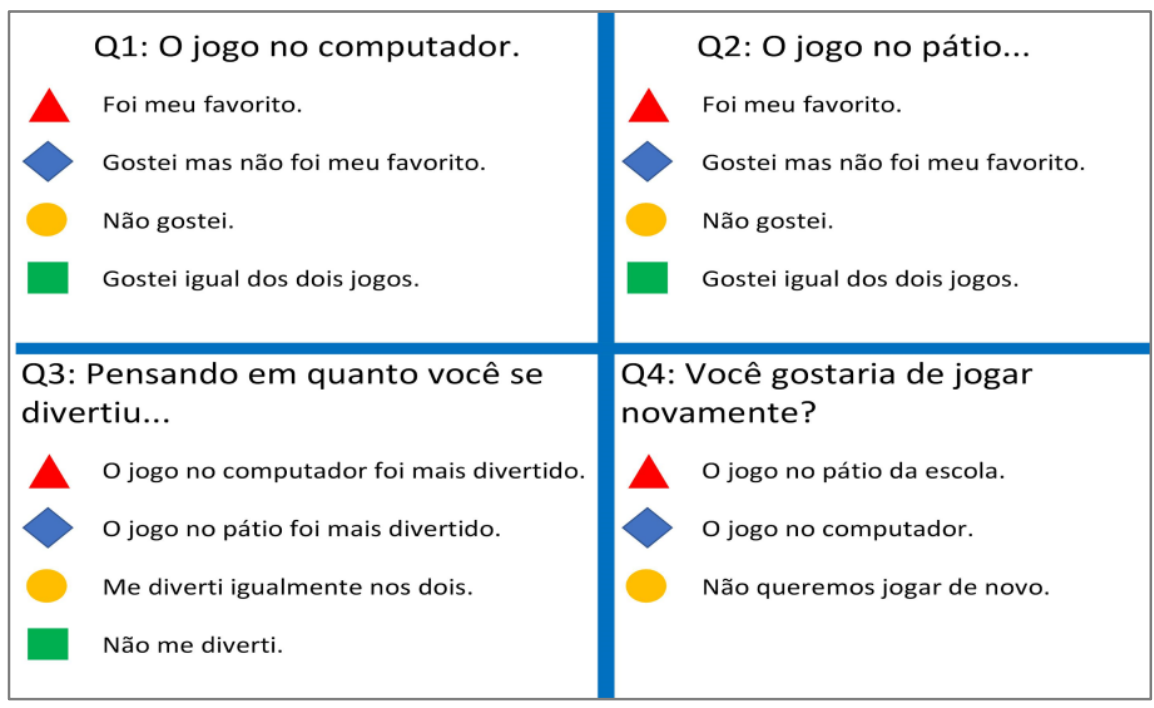

Fonte: Arquivo dos autores.

Através das respostas individuais obtidas pelo questionário foi possível gerar um gráfico por grupo, que pode ser observado na Figura 5. Destacando que o grupo que ganhou no jogo digital, preferiu esta atividade. O mesmo não ocorre com o grupo vermelho que ganhou na atividade desplugada, em que preferiu os dois jogos. Verifica-se o valor total de 21 alunos (100\%) em que em sua maioria, 8 alunos (38\%) preferiram os dois jogos, ou seja, tanto o digital quanto o desplugado, restando a parcela de 7 alunos (33\%) jogo digital e 6 alunos (29\%) preferiram o jogo no pátio.

Figura 5 - Gráfico da atividade escolhida pelos alunos

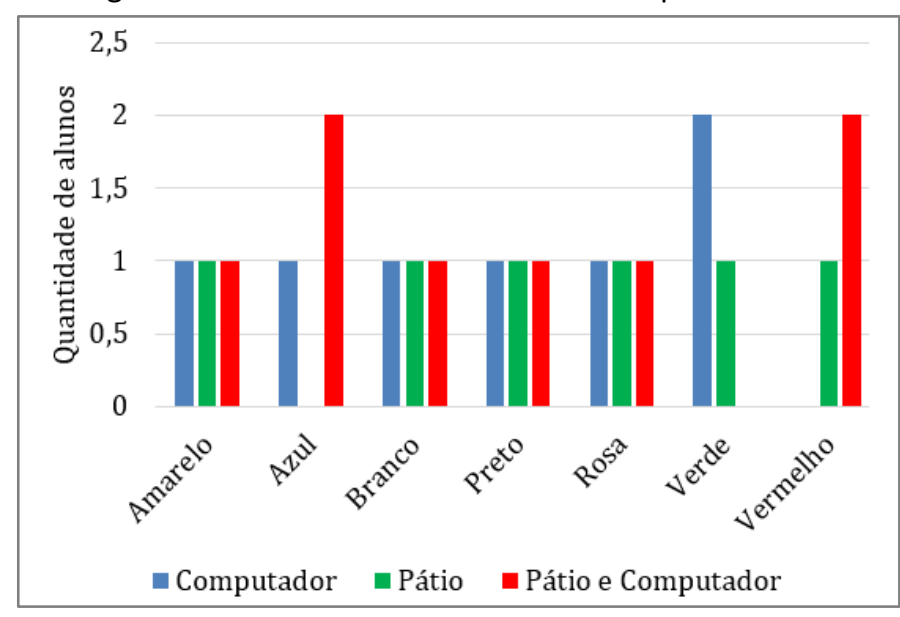

Fonte: Elaborado pelos autores.

Embora Silva e Scheffer (2019) ressaltem que os jogos computacionais promovem um encanto nas crianças e nos jovens, visto sua utilização em meios eletrônicos, o resultado da pesquisa realizada mostrou que o interesse dos alunos não estava relacionado com o formato do jogo (digital ou desplugado) mas sim com as particularidades das situações. Os resultados dessa aplicação indicam, 
com jogos está na essência do jogar, seja o jogo confeccionado de um material simples ou com a mais atual tecnologia digital".

O jogo digital teve como ponto relevante, na fala dos alunos, a agilidade na verificação das respostas (feedback), enquanto o desplugado teve seu interesse baseado no contexto de brincadeira, dado que eles deviam disputar uma corrida para entrega das respostas. Logo, não foi o formato de apresentação que induziu o interesse, mas sim o contexto da própria brincadeira que se diferencia em cada situação.

Em relação ao desenvolvimento do cálculo mental no formato digital, como o foco era na participação direta da equipe com o computador, a primeira preocupação era de resolver a situação problema apresentada, enquanto no jogo desplugado o direcionamento imediato era a corrida, para ser o primeiro a entregar a resposta. O que acontecia, por vezes, é que eles não resolviam o cálculo na equipe, mas o responsável por apresentar a resposta efetuava o cálculo no momento da entrega. Dessa forma, pode-se verificar que o trabalho em equipe é favorecido no contexto do jogo digital.

\footnotetext{
Portanto, ensinar e aprender numa perspectiva lúdica implica numa reinvenção do ambiente pedagógico, deixando-o mais favorável às crianças e professoras, mais cooperativo e interativo. O desenvolvimento de tal perspectiva requer uma escuta e olhar (ver, sentir, tocar) sensíveis ao cotidiano da escola, constituído de movimentos que se repetem, (re)criam, inovam e renovam, sendo que o conhecimento da história e o respeito aos saberes, à diversidade diferenças dos sujeitos é requisito importante para viabilização dessas proposições (PEREIRA, 2015, p. 187).
}

A criança aprende jogando e isso faz parte de sua vida, está intrínseco nas diferentes fases do seu desenvolvimento. Por esta razão, a atividade lúdica pode ser utilizada como meio formativo na infância e na adolescência (ORTIZ, 2005).

O jogo como ferramenta de aprendizagem permitiu envolver as crianças em um trabalho em grupo de resolução de problemas e de tomada de decisão, tanto no que tange à solução das questões apresentadas, quanto na própria organização das jogadas. Além disso, em uma aula tradicional, as questões apresentadas no jogo seriam propostas como uma lista de exercícios, com pouca ou nenhuma interação entre as crianças, enquanto que no contexto que foram propostas temse o caráter lúdico do jogo, que faz parte do cotidiano das crianças, propiciando um interesse espontâneo na resolução da questões.

Sendo assim, verifica-se um novo cenário de aprendizagem, que deve ser considerado na elaboração de práticas pedagógicas envolvendo a criança e o uso das metodologias que compõem o seu contexto e sua realidade, no intuito de torná-las mais presentes e ativas na sociedade contemporânea.

\section{CONSIDERAÇÕES FINAIS}

Entender o conceito de infância e como este é construído se faz necessário para a compreensão dos pressupostos históricos e epistemológicos, os quais viabilizam a criança como um sujeito ativo socialmente. Neste sentido, destaca-se a importância da promoção de múltiplos diálogos e intersecções acerca da cultura infantil e como a mesma se apresenta nos dias atuais. 
A infância é envolvida por brincadeiras e é por elas que a criança consegue se expressar, se desenvolver, construir e reinventar.

[...] brincar contribui para o desenvolvimento integral do ser humano nos aspectos físico, social, cultural, afetivo e cognitivo. Por isso, a necessidade de conscientizar os pais, os educadores e a sociedade de que brincar faz parte de uma aprendizagem prazerosa que não é apenas lazer, é um ato de aprender (PASSOS, 2019, p. 22).

Nesse contexto é relevante que os jogos e brincadeiras façam parte estratégias de ensino no âmbito escolar, permitindo que a criança seja o protagonista do processo. Assim, é importante promover um ambiente que promova a criatividade, a relação interpessoal e o desenvolvimento cognitivo.

Esta ação, por sua vez, pode ser inspirada pelas instituições de ensino e pelos profissionais docentes, os quais podem promover e utilizar a brincadeira como parte do ensino e aprendizagem, fazendo uso do que a criança, desde cedo já sabe, que é brincar.

Essa pesquisa verifica que a brincadeira que envolve um jogo didático tem implicações nos resultados, podendo direcionar o foco da atividade para diferentes contextos. Ainda, mostra que o formato do jogo desplugado não deve ser descartado em detrimento do jogo digital, visto que ambos podem estimular o aprendizado e os resultados dependem de questões culturais, sociais e do próprio contexto de brincadeira propiciado pelo jogo.

É importante ressaltar que o objetivo de aprendizagem com o jogo seria o mesmo em uma situação tradicional, na qual as mesmas questões seriam propostas por meio de uma lista de exercícios. Porém, o jogo permite maior interesse das crianças, dado o contexto de ludicidade e de desafio, além de desenvolver o trabalho em grupo, a resolução de problemas no contexto das regras e da organização, a tomada de decisão, bem como promover um ambiente em que se aprende enquanto se brinca, que faz parte do cotidiano das crianças.

Nesse sentido, sugere-se que outras pesquisas sejam realizadas em diferentes situações sociais e de aprendizagem, para que o comparativo entre jogos digitais e desplugados possam ser amplamente discutidos. 


\title{
DIGITAL OR UNPLUGGED GAMES: PLAY OR THING SERIOUSLY?
}

\begin{abstract}
This article presents some narratives about childhood and playfulness, from the historical perspective that allow a brief analysis of the use of games as a tool in the teaching and learning of Mathematics. From this perspective, this work aims to assess the implications and what the children's preference is, when using the game as a teaching tool, both in digital format using the Kahoot! As in the version of the same in unplugged form (manual). To this end, a game was applied in order to promote the development of mental calculus related to the four fundamental operations, in a class of the second year of Elementary School. The results indicate that regardless of the form of the game, the interests are related to the particularity of the situation and not to the presentation format. Regarding learning, the development of mental calculus was stimulated equally in both versions of the game, favoring group work, the development of problem-solving and decision-making skills.
\end{abstract}

KEYWORDS: Education games. Mathematics Teaching. Kahoot. 


\section{NOTAS}

1 Este recurso está disponibilizado no endereço https://getkahoot.com.

\section{REFERÊNCIAS}

BOGDAN, R.; BIKLEN, S. Investigação qualitativa em Educação: Uma introdução à teoria e aos métodos. Portugal: Porto Editora, 1991.

BRACKMANN, C. P. Desenvolvimento do pensamento computacional através de atividades desplugadas na Educação Básica. 2017. 226 f. Tese (Doutorado em Informática na Educação) - Universidade Federal do Rio Grande do Sul, Porto Alegre, 2017.

BROUGERE, G. A criança e a cultura lúdica. Rev. Fac. Educ., São Paulo, v. 24, n. 2, p. 103-116, jul./dez. 1998.

DAMBRÓS, G.; MOURAD, L. A. P. Aprendizagem baseada em jogos digitais na infância: contribuições de Huizinga e Prensky. In: RISCAROLI, E. (Org.) Epistemologias da Infância. 1 ed. Curitiba: Appris, 2017.

FUENTES, M. T. M. Evolução do jogo ao longo do Ciclo Vital. In: MURCIA, Juan Antonio Moreno (Org.). Aprendizagem através do jogo. Porto Alegre: Artmed, 2005.

GADOTTI, M. Boniteza de um sonho: ensinar-e-aprender com sentido. Curitiba: Positivo, 2005.

GRANDO, R. C. O Conhecimento Matemático e o Uso de Jogos na Sala de Aula. 2000. Tese (Doutorado em Educação) - Faculdade de Educação, UNICAMP, Campinas, 2000.

GRANDO, R. C. Recursos didáticos na Educação Matemática: jogos e materiais manipulativos. Revista Eletrônica Debates em Educação Científica e Tecnológica, Vitória, v. 5, n. 2, p. 393-416, 2015. doi: 10.36524/dect.v5i02.117

HUIZINGA, J. Homo ludens: o jogo como elemento da cultura. 4 ed. São Paulo: Perspectiva, 1996.

KAHOOT! Disponível em: https://kahoot.com/company/. Acesso em: 20 nov. 2018. 
LEONTIEV, A. N. Uma contribuição à Teoria do Desenvolvimento da Psique Infantil. In: VIGOTSKII, Lev. Semenovich. Linguagem, desenvolvimento e aprendizagem. Trad. Maria da Penha Villalobos. São Paulo: Ícone, 1998.

ORTIZ, J. P. Aproximação teórica à realidade do jogo. In: MURCIA, Juan Antonio Moreno (Org.). Aprendizagem através do jogo. Porto Alegre: Artmed, 2005.

OLIVEIRA, B. A. H. DE; BRIM, J. DE F. H.; PINHEIRO; N. A. M. O jogo Torre de Hanói como ferramenta mediadora no ensino de potências: um estudo com os alunos do 60 ano do ensino fundamental. Revista Brasileira de Ensino de Ciência e Tecnologia, Ponta Grossa, v. 12, n. 1, p. 568-583, jan./abr. 2019. doi: 10.3895/rbect.v12n1.9698.

PASSOS, A. M. R. L. A influência das brincadeiras e dos jogos matemáticos no desenvolvimento cognitivo da criança na Educação Infantil. Pedagogia em Ação, Belo Horizonte, v. 11, n. 1, 2019. Disponível em:

http://200.229.32.43/index.php/pedagogiacao/article/view/21538. Acesso em: 12 fev. 2020.

PEREIRA, R. S. Ludicidade, infância e educação: uma abordagem histórica e cultural. Revista HISTEDBR, Campinas, n. 64, p. 170-190, set. 2015.

PRENSKY, M. Aprendizagem baseada em jogos digitais. São Paulo: SENAC, 2012.

SILVA, A. C. R. da, et al. Importância da Aplicação de Atividades Lúdicas no Ensino de Ciências para Crianças. Revista Brasileira de Ensino de Ciência e Tecnologia, Ponta Grossa, v. 8, n. 3, p. 84-103, mai./ago. 2015. doi: 10.3895/rbect.v8n3.1889

SILVA, J. B.; ANDRADE, M. H.; OLIVEIRA, R. R.; SALES, G. L.; ALVES, F. R. V. Tecnologias digitais e metodologias ativas na escola: o contributo do Kahoot! para gamificar a sala de aula. Revista Thema, v. 15, n. 2, p. 780-791, 2018.

SILVA, S. L. D. da; SCHEFFER, N. F. Aprendizagem matemática com jogos digitais online: um estudo fundamentado a partir da Neurociência. Revista de Estudos e Pesquisas sobre Ensino Tecnológico (EDUCITEC), Manaus, v. 5, n. 11, p. 4-15, jun. 2019. doi: $10.31417 /$ educitec.v5i11.665

SOËTARD, M. Jean-Jacques Rousseau. Recife: Fundação Joaquim Nabuco, 2010. 100 p. (Coleção educadores) 
Recebido: 12 abr. 2019

Aprovado: 09 set. 2020

DOI: $10.3895 /$ rbect.v13n3.9972

Como citar: SIMON, V. L. B.; SIMON, A.; POSSAMAI, J. P. Jogos digitais ou desplugados: brincadeira ou

coisa séria? Revista Brasileira de Ensino de Ciência e Tecnologia, Ponta Grossa, v.13, n. 3, p. 93-108,

set./dez. 2020. Disponível em: <https://periodicos.utfpr.edu.br/rbect/article/view/9972>. Acesso em: XXX.

Correspondência: Vanessa Lima Bertolazi Simon - vlbsimon@furb.br

Direito autoral: Este artigo está licenciado sob os termos da Licença Creative Commons-Atribuição 4.0

Internacional. 